\title{
Laser ablated micropillar energy directors for ultrasonic welding of microfluidic systems
}

Poulsen, Carl Esben; Kistrup, Kasper; Andersen, Nis Korsgaard; Taboryski, Rafael J.; Hansen, Mikkel Fougt; Wolff, Anders

Published in:

Journal of Micromechanics and Microengineering

Link to article, DOI:

$10.1088 / 0960-1317 / 26 / 6 / 067001$

Publication date:

2016

Document Version

Publisher's PDF, also known as Version of record

Link back to DTU Orbit

Citation (APA):

Poulsen, C. E., Kistrup, K., Andersen, N. K., Taboryski, R. J., Hansen, M. F., \& Wolff, A. (2016). Laser ablated micropillar energy directors for ultrasonic welding of microfluidic systems. Journal of Micromechanics and Microengineering, 26(6), [067001]. https://doi.org/10.1088/0960-1317/26/6/067001

\section{General rights}

Copyright and moral rights for the publications made accessible in the public portal are retained by the authors and/or other copyright owners and it is a condition of accessing publications that users recognise and abide by the legal requirements associated with these rights.

- Users may download and print one copy of any publication from the public portal for the purpose of private study or research.

- You may not further distribute the material or use it for any profit-making activity or commercial gain

- You may freely distribute the URL identifying the publication in the public portal 
Laser ablated micropillar energy directors for ultrasonic welding of microfluidic systems

This content has been downloaded from IOPscience. Please scroll down to see the full text.

2016 J. Micromech. Microeng. 26067001

(http://iopscience.iop.org/0960-1317/26/6/067001)

View the table of contents for this issue, or go to the journal homepage for more

Download details:

IP Address: 192.38.67.115

This content was downloaded on 27/04/2016 at 11:08

Please note that terms and conditions apply. 


\title{
Technical Note
}

\section{Laser ablated micropillar energy directors for ultrasonic welding of microfluidic systems}

\section{Carl Esben Poulsen, Kasper Kistrup, Nis Korsgaard Andersen, Rafael Taboryski, Mikkel Fougt Hansen and Anders Wolff}

\author{
Department of Micro- and Nanotechnology, Technical University of Denmark, DTU Nanotech, \\ Building 345 East, DK-2800 Kongens Lyngby, Denmark \\ E-mail: anders.wolff@nanotech.dtu.dk
}

Received 19 November 2015, revised 10 February 2016

Accepted for publication 29 February 2016

Published 20 April 2016

\begin{abstract}
We present a new type of energy director (ED) for ultrasonic welding of microfluidic systems. These micropillar EDs are based on the replication of cone like protrusion structures introduced using a pico-second laser and may therefore be added to any mould surface accessible to a pico-second laser beam. The technology is demonstrated on an injection moulded microfluidic device featuring high-aspect ratio $(h \times w=2000 \mu \mathrm{m} \times 550 \mu \mathrm{m})$ and free-standing channel walls, where bonding is achieved with no detectable channel deformation. The bonding strength is similar to conventional EDs and the fabricated system can withstand pressures of over 9.5 bar.
\end{abstract}

Keywords: ultrasonic welding, polymer fusion, microfluidics, bonding, injection moulding

S Online supplementary data available from stacks.iop.org/JMM/26/067001/mmedia

(Some figures may appear in colour only in the online journal)

\section{Introduction}

In academia, soft imprint lithography with polydimethylsiloxane (PDMS), sealed using plasma activated bonding, is by far the most-used route for rapid prototyping of microfluidic systems [1]. The high elasticity of PDMS allows for the fabrication of advanced valves and gates, and its good solvent compatibility enables the use of multiphase liquid systems [2]. For commercial production, however, hot embossing or injection moulding (IM) combined with ultrasonic welding (UW) are more common for high throughput fabrication of low-cost disposable devices [3]. Since the physical and chemical properties of thermoplastics differ significantly from those of PDMS, the transfer of the technology from academia to industrial production may prove unfeasible or require the fabrication process to be completed redesigned [3].
Moreover, PDMS has fabrication limitations compared to thermoplastics [4]; for example, its high elasticity and self-adhesion may induce the collapse of high- [5] and low- [6] aspect ratio channels and structures via self-adhesion. Thermoplastics, on the other hand, are generally stiffer and less self-adhering. Recently, we presented ultrasonically welded, injection moulded, large area, low-aspect ratio cyclic olefin copolymer (COC) devices [7, 8], where the fabrication in PDMS of similar devices has traditionally relied on embedded glass slides to achieve sufficient rigidity [9]. Similarly, high-aspect ratio features in PDMS devices can only be realised by the use of sacrificial moulding methods [10], where these features have to be structurally supported by a solid bulk part [11]. Many techniques for the bonding of thermoplastic devices require elevated temperatures and/or high pressures [12-15], which may cause structural 


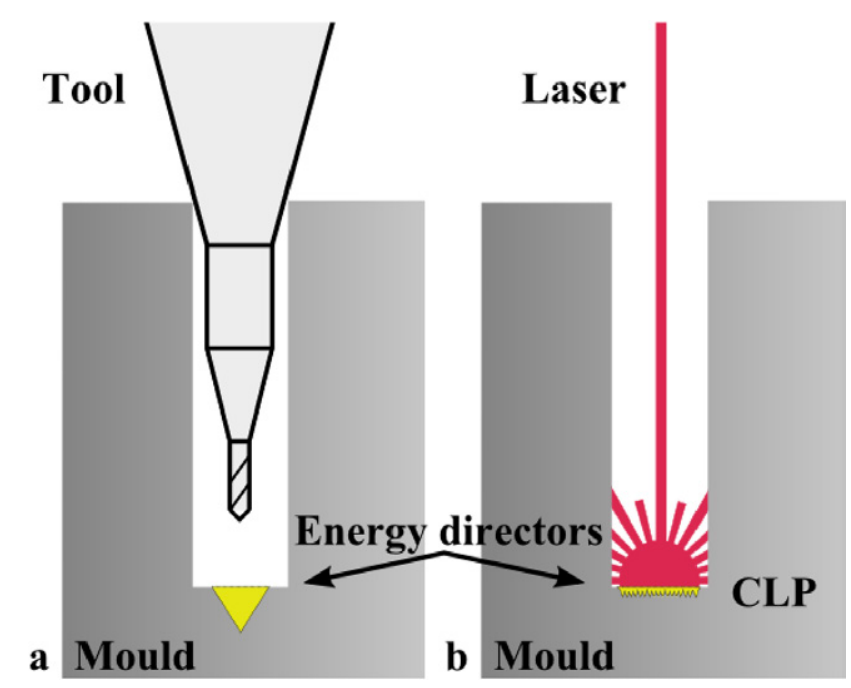

Figure 1. Schematics of methods for introducing ED forming grooves in moulds. (a) Conventional EDs introduced by micromilling (or electric discharge machining). (b) Laser ablated CLPs. Removed material is highlighted in yellow.

deformation, and the bonding of high-aspect ratio structures is therefore not easily realized. UW, on the other hand, is a fast back-end bonding process, and may be conducted at relatively low pressures and at room temperature. However, it requires the addition of energy director (ED) structures protruding on top of the channel walls. For device fabrication based on replication techniques (e.g. hot embossing and injection moulding), the tool has the inverse structure and the ED structures thus have to be realized as depressions in the bottom of the cavity structure used to define the channel wall. ED structures can be realized, e.g. by micro-milling, which is a rapid mould tool fabrication process, but the size of the milling tool limits their dimensions. Milling tools are made as small as 10-50 $\mu \mathrm{m}$, yet it is often not feasible to make EDs on high-aspect ratio wall structures in this way, since the drill aspect ratio is often limited to 1:3, and the micro mills are short and mounted on large shanks (figure 1(a)).

In this paper, we present a new type of micropillar EDs for UW of microfluidic systems. These EDs are formed by introducing cone-like protrusion (CLP) structures [16] as a back-end process into replication moulds using a picosecond laser. They have the substantial advantage over traditional EDs that they can be defined on any surface accessible to a high energy pico-second laser beam (figure 1(b)). Moreover, these EDs can be introduced in designated areas on the tool, and the width of these areas can be chosen independently from the heights of the EDs. This is in contrast to traditional EDs, where larger widths are accompanied by higher structures. The CLPs are formed stochastically within the designated area, so only ablation of the general ED shape is required, not the individual CLPs. We demonstrate the technology in an aluminium mould, but also verify the CLP formation in tool steel used for industrial moulds. To characterise the performance of this new type of EDs, we compare CLP-EDs to micromilled EDs with respect to (1) welding strength, (2) structural deformation of a free-standing high-aspect structure, and (3) formation of particles during welding (any formed particles may interfere with the function of the microfluidic device [17]). The results of particle forming are presented in the supplementary information (stacks.iop.org/JMM/26/067001/mmedia).

\section{Materials and methods}

\subsection{Chip fabrication}

Injection moulding was carried out using a custom-made moulding tool comprising a $50 \mathrm{~mm}$ diameter disk cavity with 12 luer inlets [7, 8, 12, 13, 18, 19]. The tool could be combined with mould inserts with structures machined in aluminium 2017 (A12017) [19]. Prior to injection moulding, two types of ED structures were introduced: (1) Traditional EDs introduced by micro-milling using a $60^{\circ}$ helical engraving tool (\#7025, DIXI Polytool, Le Locle, Switzerland). An apex depth of $100 \mu \mathrm{m}$ was used (width $=115 \mu \mathrm{m}$ ). (2) Microstructured CLP-EDs written using a FUEGO $1064 \mathrm{~nm}$, $50 \mathrm{~W}$ picosecond laser (Time Bandwidth, 3D-Micromac AG, Chemnitz, Germany) mounted in a microSTRUCT vario (3D-Micromac AG). CLPs were introduced by scanning designated areas with parallel lines (10 $\mu \mathrm{m}$ spacing), which was repeated 20 times at $50 \%$ power and $1000 \mathrm{~mm} \mathrm{~s}^{-1}$ with the focus plane $1.3 \mathrm{~mm}$ above the surface (green lines in figure 3 ). The writing time was $200 \mathrm{~s} \mathrm{~cm}^{-2}$. These settings were similar to the work by Brüning et al in 2014 [16], but the tuning of parameters was conducted towards higher roughness. As demonstrated by Wu et al [20], the dimensions of the CLPs may be tailored by the laser parameters. In this study, we aimed for CLPs slightly higher than $10 \mu \mathrm{m}$, since smaller EDs generally require specialised levelling systems to achieve satisfactory welding [21].

To confirm the commercial relevance of the technology, we also demonstrated the writing of CLPs in high performance tool steel Orvar2343 (MetalCentret, Glostrup, Denmark). Al2017 was preferred for mould making in this low-volume academic setting study due to its ease for machining.

The injection moulding was carried out on a Victory 80/45 Tech hydraulic injection moulding machine (Engel, Schwertberg, Austria) using COC grade 5013L-10 (TOPAS Advanced Polymers GmbH, Frankfurt-Höchst, Germany) with injection and mould temperatures of $270{ }^{\circ} \mathrm{C}$ and $120{ }^{\circ} \mathrm{C}$, respectively. Injection pressure was 1766 bar and the process cycle time was $45 \mathrm{~s}$ per part.

Fabricated chips were bonded to a $500 \mu \mathrm{m}$ thick foil of COC grade 5013S-04 (TOPAS Advanced Polymers GmbH) by UW. This was performed at ambient temperature using a Telsonic-USP4700 ultrasonic welder (Telsonic, Erlangen, Germany), depositing $25 \mathrm{~J}$ with $75 \%$ vibrational amplitude, a trigger force of $400 \mathrm{~N}$ and 0.5 bar vertical welding pressure. With the fitted $2 \times$ booster and flat sonotrode $\left(78 \times 115 \mathrm{~mm}^{2}\right)$, the vibrational amplitude normal to the sample surface was approximately $44 \mu \mathrm{m}$. See figure 2 for schematics of the ultrasonic welding process utilised. A video of the UW process described is found in the supplementary information (stacks. iop.org/JMM/26/067001/mmedia). 


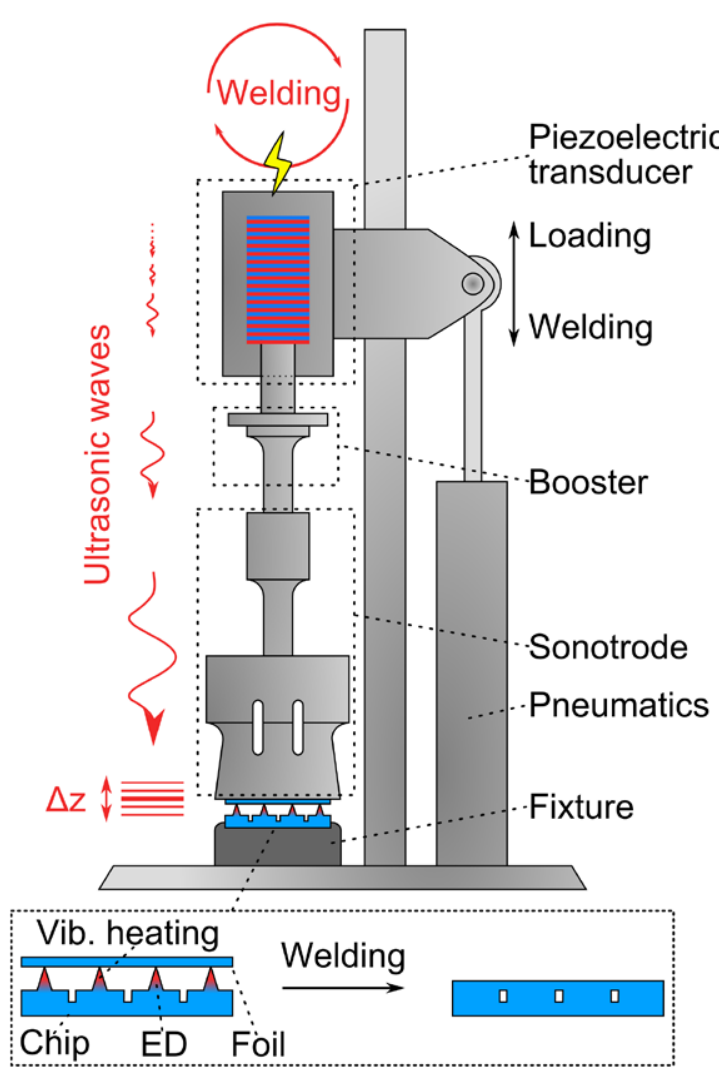

Figure 2. Schematic of the ultrasonic welding machine used in this study. Prior to welding, the pneumatic cylinder is set to the welding pressure $(0.5$ bar $)$, clamping the foil and chip together vertically. Next, the piezoelectric transducer generates a downward $20 \mathrm{kHz}$ pulse of ultrasonic waves which is then amplified and shaped to a planar wave in the booster and sonotrode. Finally, the ultrasonic waves are transferred from the vibrating underside of the sonotrode to the polymer foil (sonotrode amplitude, $\Delta z=44 \mu \mathrm{m}$ ). Here they cause local heating and melting of the EDs due to the high energy density caused by the low contact area. As the foil and chip fuse, the contact area increases and the heating terminates. (Inset) close-up (not to scale) of polymer chip with EDs (not to scale) pre welding (left) and post welding (right). Vibrational heating is highlighted in red.

\subsection{Bonding strength}

The bonding strength was assessed using the razor-blade test based on fracture propagation developed by Maszara et al [22], and employed by Matteucci et al [13] to assess the strength of thermal bonding in similar chips. To perform the test, two flat mould inserts with a milled $5.15 \times 42.5 \times 0.25 \mathrm{~mm}^{3}$ cavity were fabricated by micro-milling. In this cavity, the first insert further featured a $40.5 \mathrm{~mm}$ long conventional ED made by conventional milling and the second insert featured a laser micromachined ED with CLPs on an area of $40.5 \times 0.2 \mathrm{~mm}^{2}$. The resulting injection moulded parts thus featured $0.25 \mathrm{~mm}$ high plateaus with the respective EDs on top. The parts were bonded to a COC foil as described above. Details of the razor-blade testing as well as the results on all chips are given in the supplementary material (stacks.iop.org/JMM/26/067001/mmedia).

\subsection{High-aspect ratio microfluidic system}

UW of free-standing structures was demonstrated on an intertwining microfluidic system consisting of two $400 \mu \mathrm{m}$ wide channels. These channels are separated by $2000 \mu \mathrm{m}$ high, $550 \mu \mathrm{m}$ wide, free-standing walls with a $200 \mu \mathrm{m}$-wide band of micropillar EDs on top (figure 3). Note that these EDs cannot be fabricated by conventional methods due to the small size of the structures and the large aspect ratio. The microfluidic system spanned a $36.3 \times 25.8 \mathrm{~mm}^{2}$ rectangle. Note that the $200 \mu \mathrm{m}$ wide ED structure in expanding regions was separated into two bundles of ten lines, keeping a constant wall-to-edge distance of $180 \mu \mathrm{m}$ (figure 3(c)).

Channel deformation was characterised along four cross sections using confocal microscopy, with a Zeiss LSM 700 with voxel sizes of $X \times Y \times Z=0.313 \times 0.313 \times 5.387 \mu \mathrm{m}^{3}$. The location of the cross sections and the bonded chip are shown in figures 3(a) and (b), respectively.

\section{Results and discussion}

\subsection{CLP and ED structures}

Figures 4(a) and (b) show scanning electron microscopy (SEM) images of the CLPs written in the al2017 mould. It is of note that although the laser scanning is conducted in bundles of parallel lines, the formed CLPs are stochastically formed within the laser ablated area. This may be ascribed to the fact that the microphase explosions causing the CLPs are caused by a combination of metal impurities (alloy) picking up the energy, the pulsing nature of the laser beam and non-uniformity of the laser fluence distribution [20]. The CLPs have a typical height and spacing of $10 \mu \mathrm{m}$ and $10 \mu \mathrm{m}$, respectively. On average, the CLP area protrudes $47 \mu \mathrm{m}$ from the plane of the part wall (figure $5(\mathrm{~g})$ ). Note that the CLPs are locally convex depressions in the mould which therefore facilitate easy demoulding during replication. Figure 4(c) shows a SEM image of a COC cast of the mould. The replicated structures are observed to have rounded tops due to imperfect filling during replication. We found that operating at conditions yielding higher fidelity replication resulted in more difficult demoulding, due to stronger adhesion between the mould and its replica. This rounding did not affect the performance of the EDs and attempts to achieve more pointed structures and better replication in the $z$-direction were therefore not pursued. Figure 4(d) shows tool steel Orvar2343 ablated to produce CLPs similar to those demonstrated in al2017.

Figures 5(a) and (b) show SEM images of the CLP-EDs in the al2017 mould for fabrication of the high-aspect ratio microfluidic system. The images clearly show the feasibility of writing CLP-ED structures at the bottom of the trenches in the mould. Note that the separation and joining of bundles of laser lines do not alter the pattern and formation of CLPs. Thus, CLP-EDs can be formed in any pattern or geometry. Corresponding SEM images of the injection moulded COC part (figures 5(c) and (d)) clearly show that micropillar structures are well reproduced laterally on the top of the highaspect ratio wall.

Figures 5(e) and (f) show optical micrographs of a section of the wall of a moulded part pre and post UW. Due to the structure of the CLPs, the final micropillar CLP-EDs of the polymer chip are opaque (figure 5(e)). However, like 

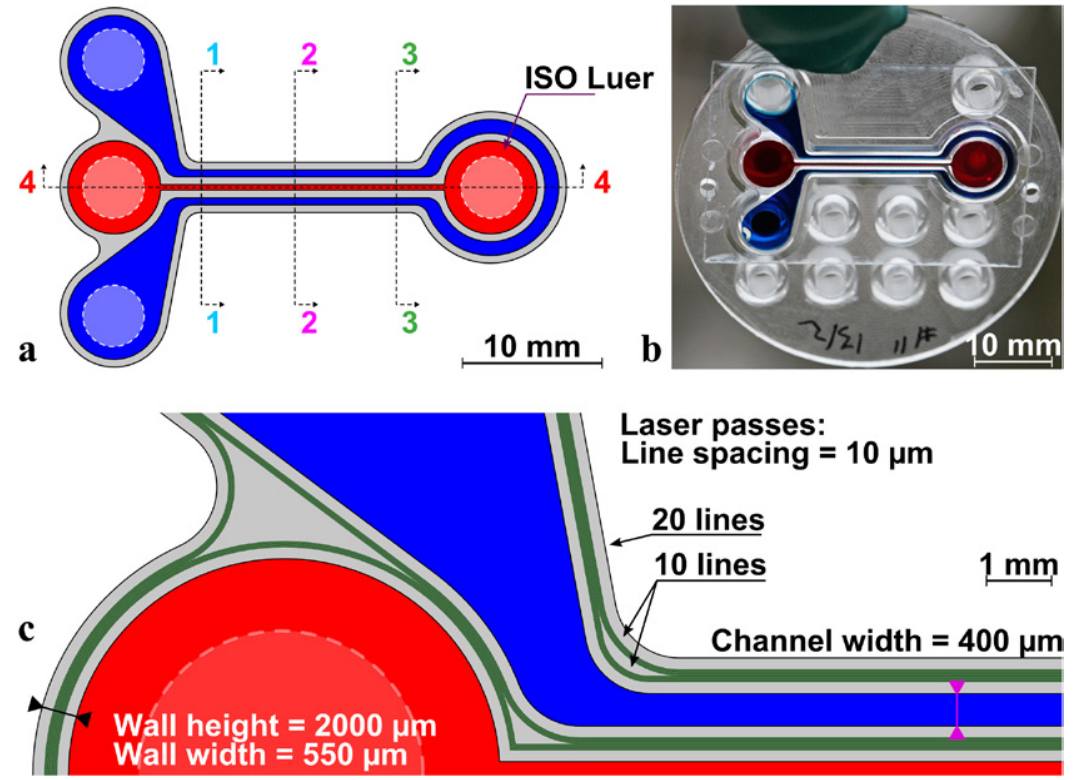

Figure 3. (a) Schematic drawing of high aspect ratio chip. Blue: outer channel, red: inner channel, and gray: walls. Cross-sections 1-4 for confocal imaging are indicated. (b) Image of bonded chip filled with dye solutions for highlighting channels. Note that the sealing lid only contacts the walls. (c) Chip with laser patterning lines added (green). Note that the 20 lines are separated into two bundles at the corners, to keep a constant edge distance $(180 \mu \mathrm{m})$.
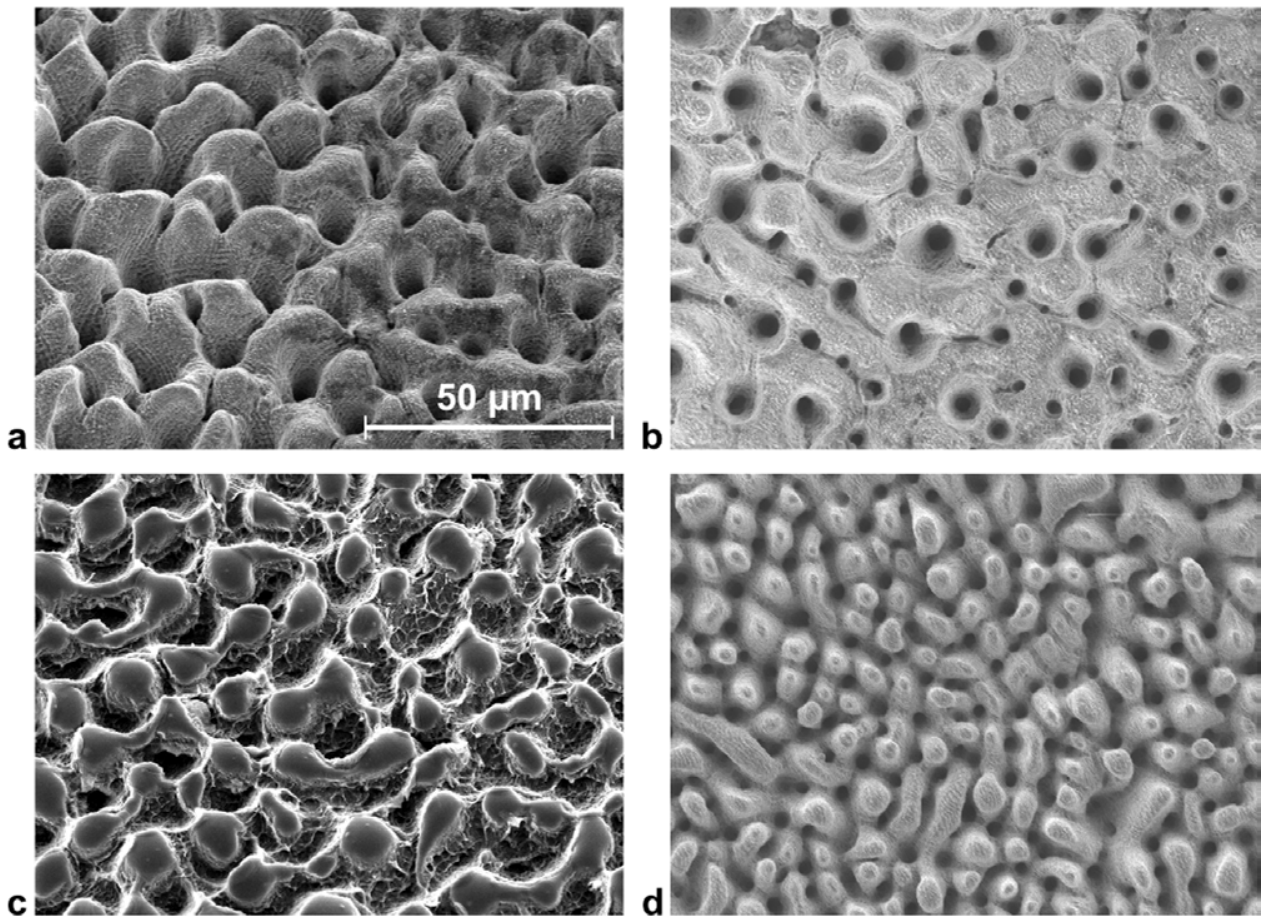

Figure 4. (a) and (b) SEM images of CLPs in al2017 moulds $\left(30^{\circ}\right.$ and $0^{\circ}$ tilt, respectively) and (c) replicated COC $\left(30^{\circ}\right.$ tilt). (d) Industrial mould making steel Orvar2343 modified using the presented technology $\left(0^{\circ}\right.$ tilt $)$.

conventional butt joint EDs [8], the joints are transparent post welding (figure 5(f)). It is worth noting that no signs of trapped or compressed air are observed in the corner section, where the CLP-EDs are split (figure 5(e)). Little or no gap is observed post UW in figure 5(f). This indicates that the micropillar structure does not trap air during UW, which would otherwise lead to hazy and weakened bonds. SEM images in figures $5(\mathrm{~g})$ and $(\mathrm{h})$ show an unbonded and bonded chip, respectively, cleaved to show a cross section of the top of the walls. Good polymer control was achieved, evident by the position of the polymer comprising the CLP-EDs pre and post welding, as little or no flash formed (polymer spilling into the channel).

\subsection{Bonding strength}

Bonding strengths in terms of the surface energy, $\gamma$, calculated from razor-blade tests are listed in table 1 . Bonding strengths 

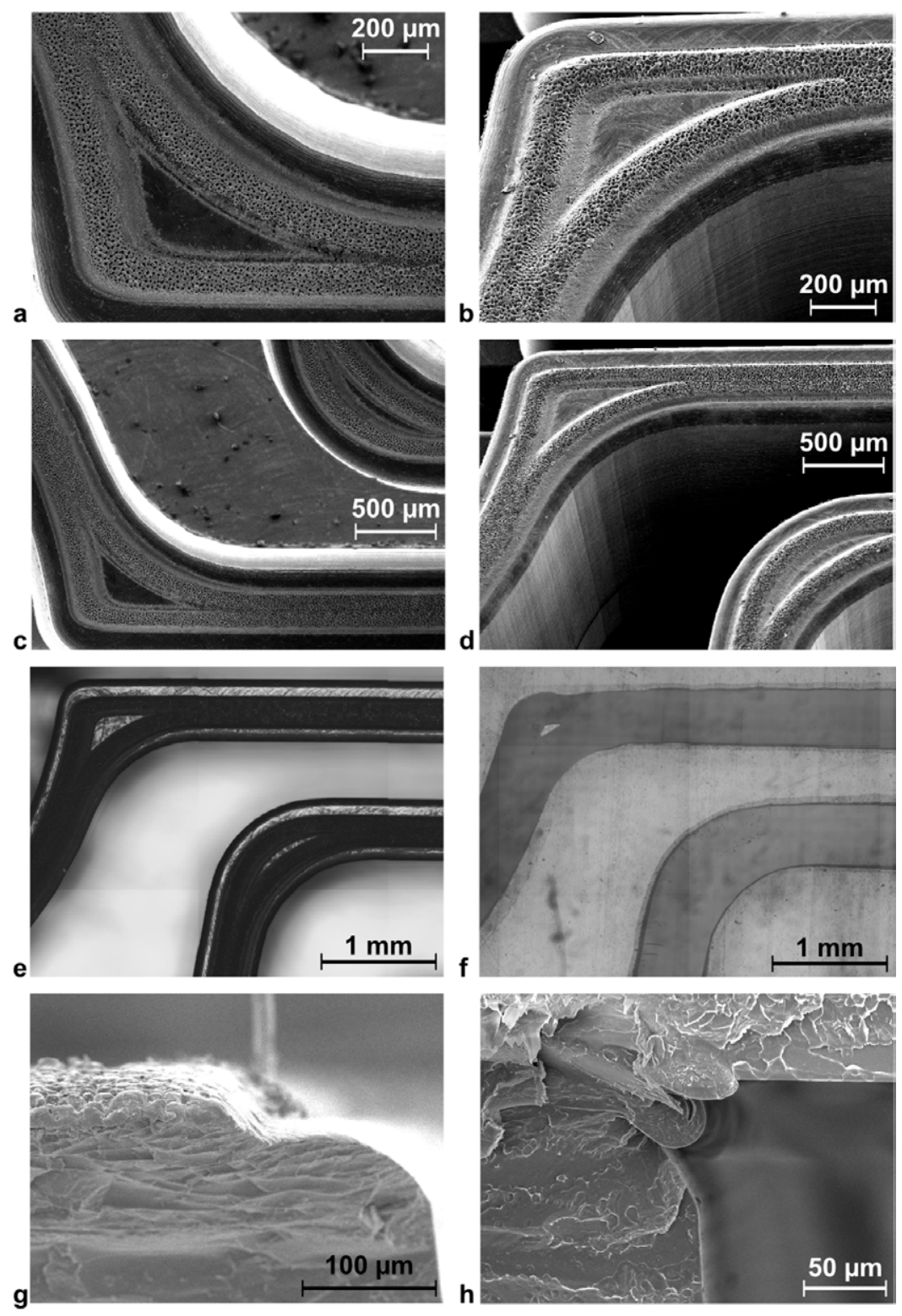

Figure 5. (a) and (c) SEM images of modified mould on indicated length scales. (b) and (d) SEM images of injection moulded piece, 30 degrees tilt. (e) Micrograph of unbonded micro pillar EDs and (f) bonded. Note the transparent welding seam. (g) Cross-sectional SEM images in direction 2 of figure 3(a) of unbonded, cleaved, and (h) bonded, cleaved, chips. Note the solidified polymer from the welding process in (h).

for other materials and bonding methods commonly used in microfluidics are also listed. These were calculated from channel dimensions and channel burst pressures. The bonding strength measurements and calculations are given in the tables $\mathrm{S} 1$ and $\mathrm{S} 2$ in the supplementary information.

Table 1 clearly shows that the bonding strength for thermoplastics is largest for structures bonded using UW. No significant difference is observed between conventional EDs and CLP-EDs. UW likely provides the strongest bonding because the substrate is not chemically altered (e.g. bond breakage by UV radiation or plasma activation for thermal bonding), and the bonding strength is thus limited by the bulk strength of the substrate. In high-pressure applications, it is important to note that the upper limit pressure (burst pressure) of a device is determined by two additional factors: the geometry and Young's modulus [27]. A softer material will flex more and result in larger forces in junctions (cracks) [27]. This explains why most PDMS devices burst at pressures lower than 6 bar $[25,26]$, even when covalent bonding methods are used [25].

\subsection{High-aspect ratio microfluidic system}

The performance of CLP-ED structures were tested in the described high-aspect ratio microfluidic system. First, we verified that the microfluidic channels were leak-tight (see figure 3(b)). Further, pressure testing with gas applied to the outer channel while leaving the inner channel at ambient pressure showed that the devices (three were tested) could sustain pressure of up to at least 9.5 bar (the maximum pressure available in our laboratory).

Figure 6 shows confocal scans of the free-standing wall structures of the device along the cross sections 1-4 (see 
Table 1. Bonding strength results expressed in terms of surface energy, $\gamma$.

\begin{tabular}{lll}
\hline Bonding method & Material & $\gamma\left(\mathrm{J} \mathrm{m}^{-2}\right)$ \\
\hline UW, conventional EDs (this study) & COC Topas 5013 L-10 & $100 \pm 30^{\mathrm{b}}$ \\
UW, CLP-EDs (this study) & COC Topas 5013 L-10 & $122 \pm 23^{\mathrm{b}}$ \\
UV activated thermal bonding [13] & COC Topas 5013 L-10 & 61 \\
UV/ozone thermal bonding [14] & COC Zeonor 1020 R & 8.1 \\
Solvent bonding, cyclohexane [23] & COC Topas 8007 & $6.2^{\mathrm{a}}$ \\
Plasma + thermal bonding [15] & COP ZEONEX & 8 \\
Solvent bonding, 75\% acetone [24] & PMMA & 13.6 \\
Oxygen plasma [25, 26] & PDMS & $44.4 \pm 2^{\mathrm{a}}$ \\
Uncured PDMS as adhesive [25] & PDMS & $227^{\mathrm{a}}$ \\
\hline
\end{tabular}

a These surface energies from the literature are calculated from the channel dimensions, Young's modulus, and bursting pressure. See supplementary information for calculations.

${ }^{\mathrm{b}}$ A two-sample (unpaired) $T$-test showed no significant difference in the bonding strength between conventional EDs and CLP-EDs: $t(10)=-1.84$, $p=0.084$.

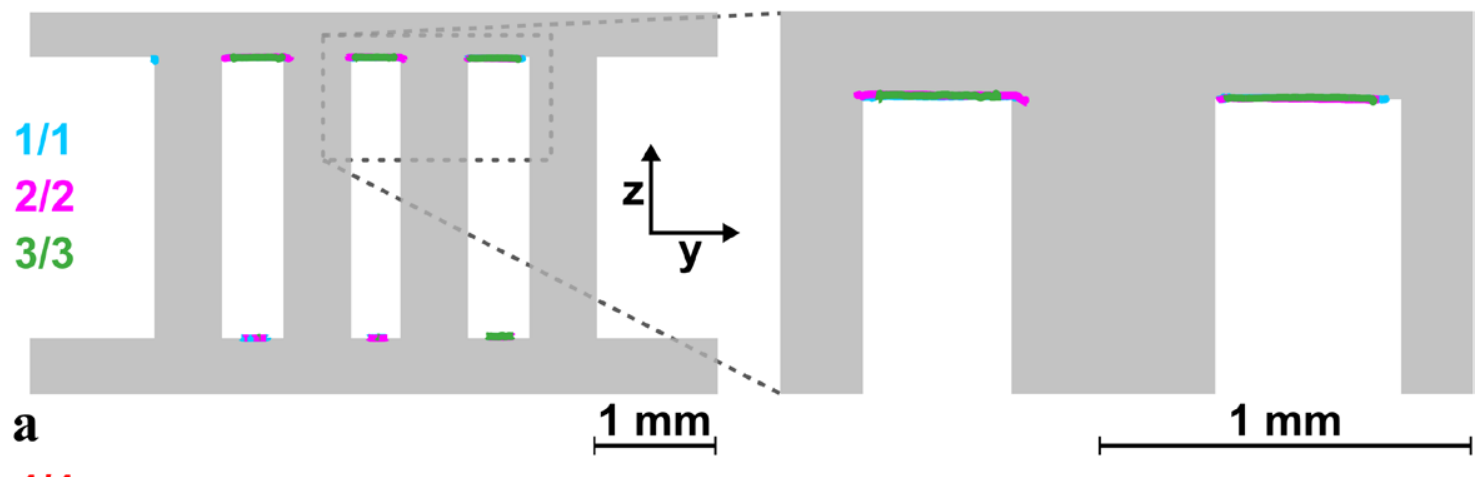

$4 / 4$

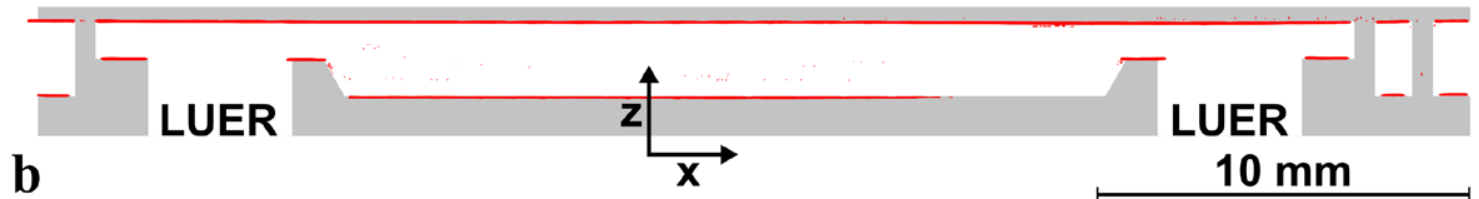

Figure 6. $2 \mathrm{D}$ cross-sections $1-4$ of bonded chips. The cross sections are denoted by labels and colour identical to figure 3 . These $2 \mathrm{D}$ images are generated from the confocal image stacks by averaging 100 cross-sections along the $x$-axis (top figures) or $y$-axis (bottom figure). This corresponds to averaging over a length of $31.3 \mu \mathrm{m}$. The data is overlaid on the chip CAD file (grey). Dashed box: close-up of the data.

figure 3(a)). The images are overlaid with the corresponding CAD file used for the mould fabrication. From the confocal scans, we find that the channel height of the welded structure matches that of the design $(2000 \mu \mathrm{m})$ with a tolerance of $\pm 4.2 \mu \mathrm{m}$. This value is smaller than the confocal image voxel height of $5.387 \mu \mathrm{m}$ and we conclude that any height difference is below our detection limit.

\section{Conclusion}

We presented a new type of ED for ultrasonic welding (UW) of microfluidic systems based on micropillar EDs. These are based on replication of CLPs in aluminium, formed using a picosecond laser, and can be added to any mould surface accessible to a high power pico-second laser. We have demonstrated the technology by injection moulding microfluidic devices featuring high-aspect ratio structures and shown that UW of the devices is possible with no detectable channel deformation. This would be impossible using conventional bonding methods that involve high pressures and temperatures. We have characterised the performance of the CLP-EDs and found that bonding strength is similar to conventional EDs, with no particle formation. The bonded devices could withstand 9.5 bar of pneumatic pressure without fracturing.

Most importantly, the technology has been demonstrated to work with high endurance tool steel used for making high performance injection moulding tools, which is a necessity for commercial applications. In addition, with a modification rate of $200 \mathrm{~s} \mathrm{~cm}^{-2}$ and full 3D capabilities, the technology is fast and allows for the addition of CLP-EDs in existing moulds regardless of their origin, be it electric discharge machining, micro-milling or cleanroom fabrication (electroforming).

\section{Acknowledgments}

This work is funded by DTU Nanotech and the Danish Council for Strategic Research through the Strategic Research Centre PolyNano (Grant no. 10-092322/DSF). 


\section{References}

[1] Waldbaur A, Rapp H, Länge K and Rapp B E 2011 Let there be chip - towards rapid prototyping of microfluidic devices: one-step manufacturing processes Anal. Methods 32681

[2] Sia S K and Whitesides G M 2003 Microfluidic devices fabricated in poly(dimethylsiloxane) for biological studies Electrophoresis 24 3563-76

[3] Becker H 2010 Mind the gap! Lab Chip 10 271-3

[4] Mukhopadhyay R 2007 When PDMS isn't the best Anal. Chem. $793248-53$

[5] Roca-Cusachs P, Rico F, Martínez E, Toset J, Farré R and Navajas D 2005 Stability of microfabricated high aspect ratio structures in poly(dimethylsiloxane) Langmuir 21 5542-8

[6] Huang Y Y, Zhou W, Hsia K J, Menard E, Park J U, Rogers J A and Alleyne A G 2005 Stamp collapse in soft lithography Langmuir 21 8058-68

[7] Kistrup K, Poulsen C E, Hansen M and Wolff A 2015 Ultrasonic welding for fast bonding of self-aligned structures in lab-on-a-chip systems Lab Chip 15 1998-2001

[8] Poulsen C E, Wootton R C R, Wolff A, DeMello A J and Elvira K S 2015 A microfluidic platform for the rapid determination of distribution coefficients by gravityassisted droplet-based liquid-liquid extraction Anal. Chem. 87 6265-70

[9] Hatch A C, Fisher J S, Tovar A R, Hsieh A T, Lin R, Pentoney S L, Yang D L and Lee A P 2011 1-million droplet array with wide-field fluorescence imaging for digital PCR Lab Chip 11 3838-45

[10] Kung Y-C, Huang K-W, Fan Y-J and Chiou P-Y 2015 Fabrication of 3D high aspect ratio PDMS microfluidic networks with a hybrid stamp Lab Chip 15 1861-8

[11] Natarajan S, Chang-Yen D A and Gale B K 2008 Large-area, high-aspect-ratio SU-8 molds for the fabrication of PDMS microfluidic devices J. Micromech. Microeng. 18045021

[12] Tanzi S, Østergaard P F, Matteucci M, Christiansen T L, Cech J, Marie R and Taboryski R 2012 Fabrication of combined-scale nano- and microfluidic polymer systems using a multilevel dry etching, electroplating and molding process J. Micromech. Microeng. 22115008

[13] Matteucci M, Christiansen T L, Tanzi S, Ostergaard P F, Larsen S T and Taboryski R 2013 Fabrication and characterization of injection molded multi level nano and microfluidic systems Microelectron. Eng. 111 294-8

[14] Tsao C W, Hromada L, Liu J, Kumar P and DeVoe D L 2007 Low temperature bonding of PMMA and COC microfluidic substrates using UV/ozone surface treatment Lab Chip $7499-505$
[15] Mizuno J, Ishida H, Farrens S, Dragoi V, Shinohara H, Suzuki T, Ishizuka M, Glinsner T, Lindner F P and Shoji S 2005 Cyclo-olefin polymer direct bonding using low temperature plasma activation bonding 13th Int. Conf. Solid-State Sensors, Actuators Microsystems, 2005. Digest Technical Paper (TRANSDUCERS) vol 2 pp 1346-9

[16] Brüning S, Jenke G, Du K and Gillner A 2014 High Precision laser processing of steel surfaces with sub-ns-lasers Phys. Proc. 56 919-26

[17] Branson Ultrasonics 1975 Part Design for Ultrasonic Welding Technical Information PW-3 vol 1 (Emerson Industrial Automation) (http://www.emersonindustrial. com/en-US/branson/Products/plastic-joining/Pages/ PlasticJoiningLiterature.aspx)

[18] Andresen K Ø et al 2010 Injection molded chips with integrated conducting polymer electrodes for electroporation of cells J. Micromech. Microeng. 20055010

[19] Kistrup K, Poulsen C E, Østergaard P F, Haugshøj K B, Taboryski R, Wolff A and Hansen M F 2014 Fabrication and modelling of injection moulded all-polymer capillary microvalves for passive microfluidic control J. Micromech. Microeng. 24125007

[20] Wu B, Zhou M, Li J, Ye X, Li G and Cai L 2009 Superhydrophobic surfaces fabricated by microstructuring of stainless steel using a femtosecond laser Appl. Surf. Sci. 256 61-6

[21] Lee K G, Shin S, Kim B I, Bae N H, Lee M-K, Lee S J and Lee T J 2015 Ultrasonic assisted bonding method for heterogeneous microstructures using self-balanced zig Lab Chip 15 1412-16

[22] Maszara W P, Goetz G, Caviglia A and McKitterick J B 1988 Bonding of silicon wafers for silicon-on-insulator J. Appl. Phys. 64 4943-50

[23] Mair D A, Rolandi M, Snauko M, Noroski R, Svec F and Fréchet J M J 2007 Room-temperature bonding for plastic high-pressure microfluidic chips Anal. Chem. 79 5097-102

[24] Wan A M D, Sadri A and Young E W K 2015 Liquid phase solvent bonding of plastic microfluidic devices assisted by retention grooves Lab Chip 15 3785-92

[25] Eddings M A, Johnson M A and Gale B K 2008 Determining the optimal PDMS-PDMS bonding technique for microfluidic devices J. Micromech. Microeng. 18067001

[26] Bhattacharya S, Datta A, Berg J M and Gangopadhyay S 2005 Studies on surface wettability of poly(dimethyl) siloxane (PDMS) and glass under oxygen-plasma treatment and correlation with bond strength J. Microelectromech. Syst. 14 590-7

[27] Anderson T L 2005 Fracture Mechanics: Fundamentals and Applications 3rd edn (London: Taylor and Francis) 